\title{
UNDERSTANDING AND FOSTERING INTERACTION IN THREADED DISCUSSION
}

\author{
Robert S. Williams \\ English Language Institute \\ The American University in Cairo \\ Rachel Humphrey \\ The University of Essex
}

\begin{abstract}
This study ( $\mathrm{N}=2,826$ postings from 92 participants) examines the phenomenon of interactivity in asynchronous computer-mediated communication (ACMC), also known as threaded discussion, in the context of master's level Teaching English as a Second Language (MATESL) and Teaching English as a Foreign Language (MATEFL) courses. The study, which is grounded in a group of interrelated pragmatic, learning community, and pedagogical theories, attempts to determine when and under what conditions interactivity, here defined as a response to a previous posting, occurs. We focus on conditions that are present in interactive threaded discussions, those with low rates of serial monologuism and high rates of participant uptake. Taking interactivity as the dependent variable, we test a number of properties of individual ACMC postings to determine their relationships to interactivity. These variables include biographical properties of the writers (gender and first language (L1), role in the course) and a group of individual ACM posting properties, such the content of the posting (course related, phatic, both), whether or not the posting is interactive, the length of the posting, its intended audience, and whether or not the posting contains indicators of social presence (use of social speech, humor, naming, and more), facethreatening speech acts, and direct questions.
\end{abstract}

Data used in the study were collected from ACMC, part of a web-based graduate introduction to second language acquisition and research methods courses. Participants in the courses were from various L1 backgrounds, including American English, Polish, Korean, and Arabic. Among our findings is that while social presence markers do not predict interactivity, there does seem to be some relationship between indicators of social presence and the quality of interaction.

\section{KEYWORDS}

Distance Learning, Online Learning, Asynchronous Learning, Threaded Discussion, Interaction, Social Presence, Cognitive Presence, Length, Face-Threatening Speech Acts, Community Of Practice, Community Of Learning, Virtual Learning Network, TESL, TEFL, Naming, Questions

\section{INTRODUCTION}

In this study, we are interested in the nature of interaction in structured online courses, where a number of students and their instructors come together for the purpose of learning, and where ACMC is the primary means of interaction. We assume that these kinds of courses take place in learning communities, primarily, but not solely, because their members share a practice. We further assume, following Vygotsky [1], Lave and Wenger [2], Garrison and Archer [3], Anderson [4], and others, that interaction among 
members of learning communities is a highly beneficial, if not necessary, condition of learning. We thus investigate a corpus of ACMC postings from online courses to discover how certain properties of threaded discussion postings relate to the degree of interactivity in the courses. We measure interactivity by uptake, or how many times discussants respond to a particular posting, as opposed to posting a message which does not respond directly to another discussant's posting.

From learning community, socio-cultural, pragmatic, and online learning theoretical perspectives, we are particularly interested to know whether interactivity is related to a number of variables in ACMC postings, including the presence of speech indicating social presence, face-threatening speech acts, and direct questions; the message content of postings (course content, social talk, both); and the intended audience of postings. From a more practical perspective, we are interested in whether or not the length of postings relates to interactivity.

We also acknowledge the importance of quality in ACMC interaction, especially as this relates to the ultimate goal of a learning community, a "purposeful and worthwhile learning experience" [5]. The achievement of this goal requires not just interactivity, but interactivity in the form of content-rich and critical discourse. A thorough investigation of the quality of discourse as it relates to interactivity is not within the scope of the present study. However, in order for there to be quality interchanges among discussants, there must first be interaction, and thus it is the nature of interactive ACMC that is the focus of the present study.

\section{REVIEW OF RELEVANT LITERATURE}

Student interaction is important for learning in general; however, different views are emerging concerning what this means in the online environment. If we consider that online learning takes place in a networked virtual learning environment [6] then we must recognize the various substructures of the networked environment when analyzing the role of interaction in online learning. Following Barab et al. [7], the Virtual Learning Environment (VLE) is a network made up of the technical structures that support interaction, as well as the various kinds of interaction that occur in the VLE. Among these are people to technology, people to content, and people to people interactions. Concerning the latter, there are now well-developed theories of the role of community in online learning. The ideas of community of practice (COP) [2, 8, 9, 10] and the more pedagogically oriented but similar community of inquiry [3], when applied to online learning, view learning communities as networks of mutual support, providers of information, and carriers of the culture and corporate experience of the discipline. The concept of community is particularly important from the perspective of the sociocultural [1] and constructivist [11, 12] approaches to education that consider learning as a process of co-constructing knowledge within a social context. Learning communities, by definition, are interactive and place more of the burden of learning on the students [13]. Accordingly, a learning community provides the conditions necessary for learning, that is, a space for constructivist discourse in a cooperative and nonthreatening environment.

However, the community of practice model has been criticized for several reasons. Goodfellow and Hewling [6] question the validity of a community of practice that in reality only seems to exist because the students have to post contributions to get a grade. Jones [13] adds that even valid communities of practice tend to exist on the margins of professional fields rather than being representative of standard professional practice. In addition, he suggests that a large proportion of learners who choose to take online courses do so because they value autonomy and flexibility with the availability of a virtual learning environment and a network of weak personal ties, not because they want to be linked to a demanding community. Finally, the importance of strong social ties in learning communities is not an uncontroversial position. Jones also raises the question of whether or not the kind of social cohesion found in learning 
Understanding and Fostering Interaction in the Threaded Discussion

communities is a necessary precondition for networked learning. We will comment on this point in the discussion section.

\section{A. Interaction in Online Learning}

Anderson [4] identifies three types of student interactivity in the context of the online course: teacherstudent, student-student and student-content. He suggests that at least one of these modalities needs to function at very high levels for "deep and meaningful learning” to occur. Goodfellow and Hewling [6] consider the inherent contradiction between the commonly stated advantages of flexibility and autonomy in accessing online content on the one hand, and the emphasis on the formation of online community from many practitioners on the other. Two distinct schools of thought seem to be emerging in course designthose focusing on flexible learning, and those based in the concept of a strong online community. As stated previously, the latter applies to the data in this study.

\section{B. The Nature of Asynchronous Computer Mediated Communication}

In the online context, where it is often not possible to perceive visual and audio cues, high quality interaction is crucial for instructors to be able to accurately assess students' needs [4]. Online interaction can also encourage reflection on the course materials as well as on the learning process itself [14], which increases students' ability to apply concepts in new situations.

ACMC has proved popular as an educational tool in many institutions $[14,15]$ due to its ability to include people from any time zone or geographical location, while providing opportunities for deep, reflective discussion that some users report as being richer than face-to-face interaction $[16,17]$. This may be because of the time delay, which gives opportunities for students to reflect; refer back to source readings and frame their responses precisely [18].

With this recognition of the importance of high levels of interactivity, attention has begun to focus on the factors that make a posting interactive-in other words, how people reply to it and continue the discussion.

A recent trend in ACMC research has been the use of content analysis to describe the nature of postings [19] and also to describe specific concepts such as social presence, which researchers feel to be significant in promoting interactivity. Rourke et al. [15] defined social presence as "the ability of learners to project themselves socially and affectively into the community of inquiry." Rourke et al. developed a template for assessing social presence in ACMC, including factors such as humor, quoting others' messages and use of we, our or us. They also observed that certain elements, specifically naming and phatic comments, tended to occur in a negative correlation with the other elements of social presence.

Tu and McIsaac [20] saw social presence as "a measure of the feeling of community that the learner experiences in an online environment." They also worked with a complex set of variables including social context, online communication issues, message length and task type, assessing students' perceptions of these variables. Their findings suggest that although situations showing high social presence tend to be interactive, not all interactive situations have high social presence. A causal relationship has yet to be observed between social presence and interactivity.

Jeong [21] analyzed the online debates of 19 graduate students from a variety of linguistic backgrounds to establish if there was a connection between response time, content and interactivity. He found that, 
generally speaking, the longer the wait, the less likely it was that a message would be answered. Exceptions were found, however, in the case of critiques which, although they had a longer than average wait for an answer, were among the most interactive postings. He suggests that critiques take longer to compose than other responses due to the complex thought processes involved, but because they deal directly with participants’ opinions and work, they generate a great deal of interest and response.

Fahy and Ally [19] studied the effect of learning style on participation levels in ACMC. They administered the Kolb Learning Style Inventory, which identifies four types of learners-convergers, divergers, accommodators, and assimilators - to two classes of graduate students. They then analyzed subjects' participation in a threaded discussion both for frequency and type of participation. Their results indicate that learning style may be a predictor of the level and type of involvement in ACMC; for example, convergers made significantly more and longer contributions than divergers. Accommodators posted more contributions with the aim of scaffolding or engaging others while assimilators were more inclined to "lurk" in the discussion and observe without participating.

In summary, it appears that student learning style, message response time and content may be predictors of interactivity. Learning styles and message response time are beyond the scope of this study, but we do examine message content, particularly with respect to whether it is related to course content or is social communication. Many other factors, including social presence, could contribute to interactivity but a relationship has yet to be established. The object of this study is to identify further variables that may characterize an interactive posting.

\section{THE PRESENT STUDY}

The present study is primarily quantitative in nature, using a logistical regression procedure, discussed below. However, discussion of the results is also qualitative in nature. In the future, we hope to follow this study with another that will present a more qualitative examination of the results.

We have situated this study in a mixed theoretical framework, which includes the sociocultural and constructivists theories of learning; the online learning theories; and theories of communities of practice and learning discussed in the introduction. In addition, we draw upon various pragmatic theories, including speech act theories of Searle [22, 23], politeness theories of Grice [24, 25] Leech [26], and Brown and Levinson [27]. We focus these theories, in one way or another, on interactivity. The learning theories cited above all specify some kind of interaction as a precondition for learning. Thus, interactivity in ACMC is the dependent variable in the study.

The aforementioned pragmatic theories are relevant here because of the possible relationship of interactivity and certain speech events, known as face-threatening speech acts (FTA). These can be seen as acts hostile to a discussant in a way that threatens that person's sense of him or herself as a competent autonomous actor. Examples of such FTAs are the expression in ACMC of disagreement or dissatisfaction with a previous posting, where the competence of the other discussant(s) is called into question. Politeness theory would predict the presence of linguistic softeners, such as partial agreement or praise, where FTAs are present, in order to maintain decorum in communication. We are interested then, in examining the relationship between the presence of FTAs, with and without politeness redress, and interactivity.

Theories of the role of community in learning assume the importance of social cohesion. This can be measured in a number of ways. We follow Rourke et al. [15] and Tu and McIsaac [20] in measuring 
Understanding and Fostering Interaction in the Threaded Discussion

social presence by the use of naming, humor, and emoticons. We also discuss other possible indicators of social presence, such as the use of politeness softeners with FTAs, which are not themselves counted directly as such. Thus we examine whether or not social presence relates to interactivity.

Finally, and from a more practical standpoint, we want to know whether certain properties of postings may relate to interactivity. These include the length of a posting and whether or a posting contains a direct question.

\section{THE PARTICIPANTS AND COURSES}

There were 92 participants in the study, 91 of whom were students in two MATESL/TEFL programs. Of these, 66 were female and 26 were male. Thirty four students were taking the courses from Egypt, and all of these were in the hybrid courses. In the all-online courses, 38 students took the courses from Poland, 19 from the US. The instructor, who was the same for all seven courses, taught the courses while in Poland and the US. Though the medium of instruction of all courses was English, among the 91 students were speakers of American English, British English, Polish, Korean, Chinese, Vietnamese, Japanese, Greek, French, Palestinian Arabic, and Egyptian Arabic.

Data were gathered from seven graduate-level courses. Four of these were offered as part of the MATESL curriculum at a small university in the eastern United States. One was a research methods course and three were second language acquisition courses. All four courses were taught completely online, but were a component of a low-residency or hybrid FTF-online program, and all used the eCollege course management system. The remaining three courses were given as part of an MATEFL program at an American university in the Middle East. All were second language acquisition courses, and all were primarily delivered in face-to-face mode with data taken from a one-week online module using the WebCT course management system.

All seven courses relied on weekly threaded discussion as their main interactive forum, where each weekly discussion lasted five days. Where class size was over 10, students were divided into two separate discussion groups. Students were required to access the course website at least twice a week, at two-day intervals, and to contribute at least two postings per access. As well as contributing new postings, students were encouraged to "converse" with other students by replying to previous postings. The phenomenon of excessive serial monologuism was discussed and discouraged by the instructor. Though discussion participation was required, it was not counted as a percentage of the final grade. However, students were told that their constant participation, as well as the quality of their postings, could influence their final grades. Students were given no instructions with respect to verbal etiquette, or length of postings.

There was significant teaching presence in all seven courses, in that the instructor set the direction of each weekly discussion by posting several starter questions at the beginning of the discussion. Usually, students would begin by discussing the starter questions and then would add other topics. During the discussion, the instructor assumed the role of a codiscussant.

Finally, there was evidence of high cognitive presence in the discussions, in that $96 \%$ of postings were primarily concerned with course content.

\section{The Data}

The 92 subjects contributed 2,826 ACMC postings to the data set, which comprise a corpus in excess of 
500,000 words. The same instructor, teaching at two universities, taught all of the courses in this study.

\section{The Variables}

We coded the data for the following 11 variables, which reflect properties of the writer, the course, and the postings themselves, as seen in Table 1.

Table 1. Variables

\begin{tabular}{|c|c|c|}
\hline Category & Label & $\begin{array}{rr}\text { Variables } \\
\end{array}$ \\
\hline $\begin{array}{c}\text { Characteristics of the } \\
\text { Writer }\end{array}$ & $\begin{array}{ll} & L 1 \\
\cdot & G E N D E R\end{array}$ & $\begin{array}{l}\text { - } \quad \text { native language } \\
\text { gender }\end{array}$ \\
\hline $\begin{array}{c}\text { Characteristics of the } \\
\text { Course }\end{array}$ & $\begin{array}{ll} & \text { TYPE } \\
\text { - } & \text { STATUS } \\
\end{array}$ & $\begin{array}{ll}\text { - } \quad \text { course type (all online/hybrid) } \\
\text { - } \quad \text { course status (required/elective) }\end{array}$ \\
\hline $\begin{array}{l}\text { Characteristics of the } \\
\text { Posting }\end{array}$ & $\begin{array}{ll}\text { - } & \text { FTA } \\
\text { - } & \text { QUESTION } \\
\text { - } & \text { AUDIENCE } \\
\text { - } & \text { TOPIC } \\
\text { - } & \text { SP } \\
& \\
\text { - } & \text { NAME } \\
& \text { INTERACT }\end{array}$ & 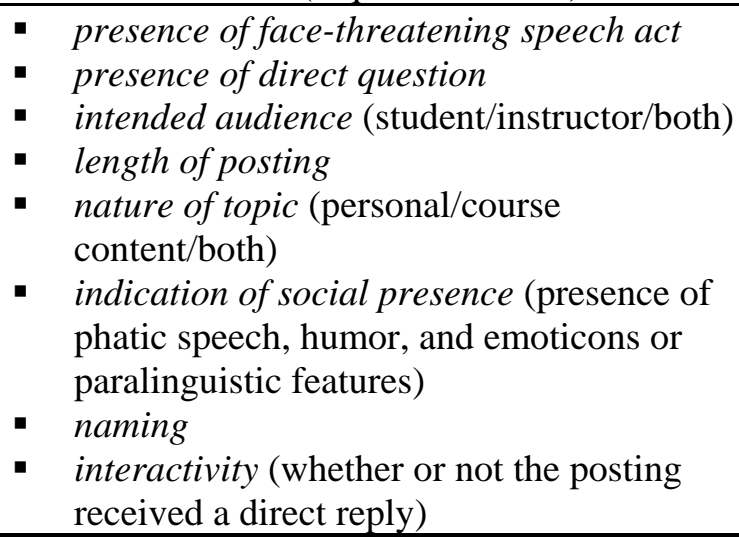 \\
\hline
\end{tabular}

These variables, all categorical, were chosen for two main reasons, having to do with methodology and theory. The dependent variable interactivity (INTERACT) is dichotomous and thus can be used with a logistical regression. The other variables can easily be quantified and thus also work well with the statistical procedure. Also, these variables fit our theoretical orientation, and thus have the potential to address some theoretical foundations of ACMC-based learning. Most of the variables are self explanatory, with the exception of the three discussed below.

\section{Face-threatening Speech Acts}

For the purpose of this study, we consider a face-threatening speech act (FTA) to be anything that reflects negatively on the competence of the reader. These include the presence of the speech acts disagreement, showing dissatisfaction with a posting in some way, and asking for clarification. In addition, this variable was coded for the presence of linguistic politeness devices, such as naming, partial agreement, praise, and self deprecation, which work to reduce threat to face, as well as face-threatening act intensifiers, such as naming and the expression of bold face disagreement. We recognize that this definition of a facethreatening act is Anglocentric, and that different cultures, or maybe even different generations will define FTAs in different ways. However, we are interested to discover whether, within an English medium online environment, awareness of what constitutes an FTA, or the lack thereof, affects the ongoing relationships within the discussion. For this reason, we decided to use the traditional model, despite its shortcomings.

So, a posting was either coded for no FTA, FTA without politeness device, FTA with politeness device, or FTA with intensifier. 


\section{Naming}

The speech act of naming (NAME) can function either as a softener, as in (1) and (2), or an intensifier as in (3) and (4) when present with FTAs. The examples below are taken from the data, though pseudonyms are used.

1) Hi Rick - Thanks for being the first to post. I think you all might be mixing up contrastive analysis theory with the idea of universal acquisitional orders...

2) Hi! Jennifer. I am not sure whether UG (universal grammar) influences IL (interlanguage) to the full extent. May be UG can be only once fully activated then UG works only via L1 to L2.

3) Katherine, even if there seem to be more outstanding men than women, you have to remember that the society didn't allow women to be special.

4) John - If you don't accept UG for L1, does that mean that you don't think there are properties universal to all natural languages?

The first two postings contain FTAs in the form of statements indicating dissatisfaction with an assertion in a previous posting. In these cases, naming, along with greetings and, in the case of (1), praise, work to decrease the intensity of the FTAs. In replies (3) and (4), however, naming seems to highlight the writers' disagreements with the postings to which they replied. It is perhaps significant that in the later two examples, where we have judged naming to be an FTA intensifier, it occurs alone. When naming occurs with politeness devices, such as agreement, in an FTA, it enhances social presence and works to lessen the threat to face in the FTA. It is also possible that naming acts as a neutral pointing device with respect to FTAs. Thus, when naming co-occurs with politeness devices in FTAs, naming points to the politeness device, having the effect of lessening the threat to face. However, when naming occurs in FTAs without politeness devices, it points to the FTA itself, thus acting to intensify the threat to face. Nguyen and Kellogg [28] find that naming occurs more frequently in their data with the expression of agreement than with disagreement. They suggest that naming is thus a device used to "build positive harmonious relationships." However, the fact that naming is also used with disagreement indicates that while it is a device used for social inclusion, social inclusion does not always equate to group harmony.

Naming seems to work as a kind of linguistic pointing device, such that when politeness devices are present, naming points to those, thus heightening their softening function, which in turn acts to lessen threat to face. In the case of FTAs where no devices are present, naming points directly to the FTA, and thus works to heighten the threat to face. This phenomenon was also noticed by Savignon and Roithmeier [29], who find that addressing a fellow discussant personally can be confrontational.

\section{Indication of Social Presence}

This study includes most of the variables which were included under Rourke et al.'s [15] definition of social presence, although some of the categories were conflated. Some of these were a specific focus of the study, specifically questions, naming and face-threatening acts, and were treated as separate variables because we wanted to determine their effect as individual features. Others such as phatic speech, humor, and emoticons or paralinguistic features were included in a single category of social presence (SP). If a posting had none of these three features, it was coded as 0 ; if one, it was coded as 1 , and so on, so that the more indicators present, the higher the social presence of a posting.

However, another indication of social presence not included in the variable SP was the presence of politeness devices with FTAs, discussed in the previous section. We believe this is also a powerful indicator of social presence, since it shows that the writer wants to minimize the possibility of a face threat to the reader, thus reducing conflict in the community of inquiry possibly enhancing interaction 
among group members. The kind of interaction brought about by an FTA is very desirable, because it enhances the quality of the discourse by engaging the participants in a "process of inquiry" [5], which in turn enhances cognitive presence, or meaningful interaction. According to the Garrison et al. [30] model of learning discussed with respect to social presence in Rourke et al. [15], the interaction of cognitive presence and social presence is a necessary condition of learning, and thus the use of politeness devices with FTAs, as a marker of social presence, might contribute to this interaction.

\section{E. Interactivity}

Postings were considered to be interactive (INTERACT) if they received a direct reply, as indicated by the threaded discussion interface schema from the course website.

Figure 1. Threaded Discussion Schema

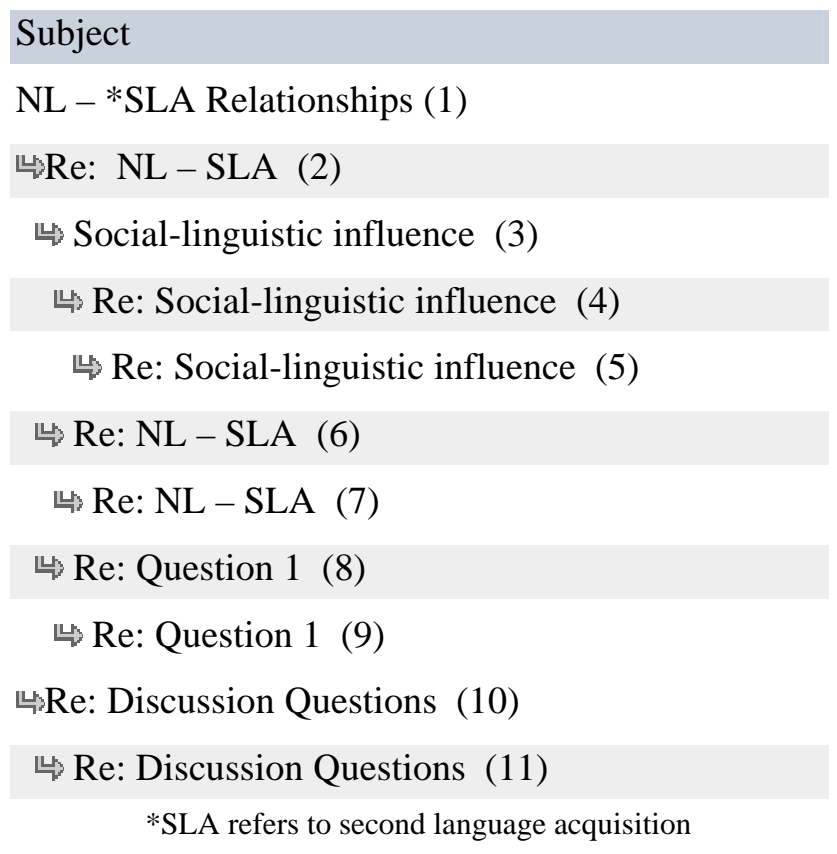

In Figure 1, all of the postings were considered interactive except numbers (5), (7), (9), and (11). It was also often the case in our data that a direct reply to one particular posting also referenced one or more other postings. For example, (7), which directly replied to (6), may also have referenced something written in (2). Due to the size of the data set, we were not able to code for this kind of secondary interactivity.

\section{F. The Quantitative Analysis}

We analyzed the data using a logistical regression procedure, which calculates maximum likelihood where there is a dichotomous dependent variable and categorical independent variables. The logistical regression procedure was chosen because of its superior ability to handle natural language data. The only other possible procedure to use with a dichotomous dependent variable is discriminant function analysis, which is not ideal to use with natural language data because it tends to bias results where independent variables are not normally distributed.

Our dependent variable was INTERACT with the other eleven variables used as independent variables 
(see Table 1). The significance level for interactivity was .05.

\section{RESULTS}

The overall model was found to be significant $\left\{\chi^{2}(11, \mathrm{~N}=2826)=235.9, \mathrm{p}<.001\right\}$. The results of the linear regression procedure were as follows. The independent variables QUESTION, AUDIENCE, and LENGTH were found to be significant, at $\mathrm{p}<.001, \mathrm{p}<.002$, and $\mathrm{p}<.001$, respectively, with respect to their relationships to the dependent variable INTERACT.

To further understand the logistical regression results, we looked at two-way Chi-square cross tabulations for each significant variable, to determine which level(s) of the significant independent variables was most closely related to INTERACT. We used the two-way Chi-square for these three variables because this allowed us to say more about the relationship between the dependent and independent variables, as is explained in 3.1.

\section{A. Direct Question}

The relationship between INTERACT and QUESTION was significant at $\chi^{2}(1, \mathrm{~N}=2826)=99.342, \mathrm{p}<$ .001 in the logistical regression procedure. The use of a two-way Chi-square procedure for these two variables tells us more about this relationship. The cell -INTERACT/+QUESTION is responsible for $45 \%$ of the Chi-square value, where there were fewer tokens than expected, and the cell +INTERACT/+QUESTION, where there were more tokens than expected, for $34 \%$ of the value. This indicates that the presence of a direct question in a posting is a predictor of positive interactivity.

Table 2. Chi-square Cross Tabulations for Interactive and Direct Question

\begin{tabular}{|l|l|l|l|}
\hline \multicolumn{2}{|l|}{} & - Direct Question & + Direct Question \\
\hline - Interactivity & Count & 1058 & 154 \\
& Expected Count & 950.1 & 261.9 \\
& Cell Contribution & $(12 \%)$ & $(45 \%)$ \\
\hline+ Interactivity & Count & 1158 & 457 \\
& Expected Count & 1265.9 & 349.1 \\
& Cell Contribution & $(9 \%)$ & $(34 \%)$ \\
\hline
\end{tabular}

\section{B. Audience}

The relationship between AUDIENCE and INTERACT was significant in the logistical regression $\left\{\chi^{2}(2\right.$, $\mathrm{N}=2826)=32.540, \mathrm{p}<.001\}$. The Chi-square for AUDIENCE and INTERACT shows that the interactivity was increased when a posting had a broad intended audience, which is when more than one person was included as the target, whether by directly naming more than one person, or by complete lack of naming. 
Table 3. Chi-square Cross Tabulations for INTERACT and AUDIENCE

\begin{tabular}{|l|l|l|l|l|}
\hline \multicolumn{2}{|c|}{} & \multicolumn{3}{|c|}{ Audience } \\
\cline { 3 - 5 } \multicolumn{2}{|c|}{} & Student & Instructor & \multicolumn{1}{|c|}{ Both } \\
\hline - Interactive & Count & 768 & 49 & 395 \\
& Expected Count & 696.2 & 48.4 & 467.3 \\
& Cell Contribution & $(22.7 \%)$ & $(0 \%)$ & $(34.4 \%)$ \\
\hline+ Interactive & Count & 856 & 64 & 695 \\
& Expected Count & 927.8 & 64.6 & 622.7 \\
& Cell Contribution & $(17.1 \%)$ & $(0 \%)$ & $(25.8 \%)$ \\
\hline
\end{tabular}

\section{Length}

The relationship between the variables INTERACT and LENGTH was also significant in the logistical regression $\left\{\chi^{2}(4, \mathrm{~N}=2826)=100.410, \mathrm{p}<.001\right\}$. The Chi-square results for these two variables show that extremely short postings are predictors of negative interactivity. We can see this because there are far more non-interactive/short postings than expected and far fewer interactive/short postings than expected. Also, longer postings, those of 251-500 and 500+ words in length were more likely than expected to be interactive. There was no statistically significant relationship between QUESTION and LENGTH ( $\chi^{2}(4$, $\mathrm{N}=2826)=.664, \mathrm{p}=.956$ ), so a possible explanation that shorter postings were less likely to contain direct questions does not hold true.

Table 4. Chi-square Cross Tabulations for Interactivity and Length of Posting

\begin{tabular}{||l|l|l|l|l|l|l||}
\hline \multicolumn{2}{|c|}{} & \multicolumn{6}{|c|}{ Length of Posting } \\
\cline { 3 - 7 } \multicolumn{2}{|c|}{} & $\mathbf{0 - 5 0}$ & $\mathbf{5 1 - 1 5 0}$ & $\mathbf{1 5 1 - 2 5 0}$ & $\mathbf{2 5 1 - 5 0 0}$ & $\mathbf{5 0 0 +}$ \\
\hline - Interactive & Count & 298 & 654 & 184 & 73 & 3 \\
& Expected Count & 225.5 & 625.1 & 234.1 & 116.2 & 11.1 \\
& Cell Contribution & $(23.2 \%)$ & $(1.3 \%)$ & $(10.7 \%)$ & $(16 \%)$ & $(5.9 \%)$ \\
\hline+ + Interactive & Count & 228 & 804 & 362 & 198 & 23 \\
& Expected Count & 300.5 & 832.9 & 311.9 & 154.8 & 14.9 \\
& Cell Contribution & $(17.5 \%)$ & $(1 \%)$ & $(8 \%)$ & $(12 \%)$ & $(4.4 \%)$ \\
\hline
\end{tabular}

\section{Role of the Instructor}

Initial qualitative analysis of the data indicates that the participation of the instructor in the discussion has different characteristics than that of the students, due to the instructor's role in eliciting information and challenging incorrect statements, and to his status. We therefore re-ran the logistical regression a second time excluding the postings contributed by the instructor to establish if these contributed to the overall effect. We found that they did not. The overall model without the instructor was also significant $\left\{\chi^{2}(11\right.$, $\mathrm{N}=2353)=194.265, \mathrm{p}<.001\}$. The two variables QUESTION and LENGTH were still significant with respect to INTERACT, each at $\mathrm{p}<.001$, but AUDIENCE $(\mathrm{p}>.037)$ was not. The overall $\chi^{2} \mathrm{~s}$ for QUESTION and LENGTH with respect to INTERACT without the instructor were similar to those where the instructor was included. Thus, these results indicate that the effect of the instructor's role is not significant with respect to overall interactivity levels in the threaded discussion. So, student discussants were no more likely to reply to the instructor's postings than to those of their fellow students.

We did note that the personal interactivity levels of individuals vary significantly. By personal interactivity, we refer to the degree to which an individual's postings are directly answered by another 
Understanding and Fostering Interaction in the Threaded Discussion

participant in the threaded discussion. The interactivity level for the corpus as a whole is $57.1 \%$, but the instructor's personal interactivity level is significantly lower at $46.2 \%$. Certain individuals among the students, by contrast, have significantly high levels of personal interactivity, for example, student 38, whose postings received direct replies $70.3 \%$ of the time. Further examination is needed to establish reasons for these differing levels, although we hypothesize here that the low instructor level of interactivity may be due to his perceived status as someone with superior knowledge and experience. This is speculation, though, since this instructor had a relatively informal relationship with the students, indicated by the students' use of his first name when addressing postings to him, making it less likely that students would challenge or query his postings.

\section{DISCUSSION}

Descriptive statistics show that $57 \%$ of all postings in the data are interactive, and that $70 \%$ contain one or more speech acts marking social presence. These statistics indicate that the courses had a high degree of interactivity and good social cohesion, though as shown previously, these two variables are not statistically significant. A much lower percentage of postings (15.6\%) contain a face-threatening speech act. Of those, $81 \%$ also show some kind of politeness softener, indicating that students feel that it is necessary to maintain a high level of politeness in ACMC discourse.

The results of our data analysis are interesting both for what they do and do not show. Beginning with QUESTION, AUDIENCE, and LENGTH, the three variables that have a significant relationship to interactivity, it was found that the presence of direct questions predicts enhanced interactivity. This result is not surprising, since a response request is inherent in the speech act of a non-rhetorical question. Direct questions also functioned as FTAs when they showed dissatisfaction in some way with a previous posting. FTAs are important for meaningful class discussions, because it is partly through disagreement and its resolution that meaning is constructed. However, for this to happen there must be dialogue, meaning that postings with FTA must be interactive. Postings with FTAs with direct questions accounted for slightly over $30 \%$ of all FTAs. When question FTAs were paired with politeness devices, those posting were more likely than expected to be interactive. This suggests that indicators of social cohesion, in the form of politeness softeners, may increase interactivity, at least in the context of FTAs. This is important, because, at least for postings with FTAs, social cohesion and interactivity quality appear to be linked. Politeness softeners seem to lead to increased interactivity for FTAs to which they are attached, and this is an indicator of the quality of interactions. Our results in this area differ from those of Jeong (2005), who found that FTAs (which he calls arguments) with politeness devices (which he refers to as qualifiers) were less interactive than those with intensifiers or with no qualifying language.

Though the variable GENDER was not found to be significant in our study, we did find a significant relationship between increased interactivity and FTAs with politeness devices written by females $\left(\chi^{2}\right.$ ( $3, \mathrm{~N}$ $=1881)=15.470, \mathrm{p}=.001)$. This relationship was neither significant for males nor for the group as a whole. Thus, our findings are in direct contradiction to Jeong's [31]. That students responded to direct questions with a significant frequency is also perhaps an indication of the social cohesion of the learning community, even though the logistical regression did not indicate that written indicators of social presence were related to interactivity.

Data for the variable LENGTH yielded results that we found somewhat counterintuitive. While it might be expected that extremely long postings would inhibit interactivity, this was not the case in our data. Very short postings, however, did correlate with low interactivity. As previously mentioned, this was not due to a lack of direct questions in short postings, or to a lack of indicators of social presence. One possible explanation for this phenomenon is that many short questions in our data were merely 
expressions of support directed at other postings. In fact, a qualitative analysis of short postings indicates that they were sometimes used by students as a means of fulfilling participation requirements without having to present new ideas, opinions, or reflections about previous postings. Short postings were also used frequently by very prolific participants, again to express support or make quick comments or jokes, as a means to build social cohesion and maintain dialogue in addition to those participants' main substantive contribution to the discussion. Extremely lengthy postings often contained complex analyses of course content, and though these are not more likely than shorter postings to contain direct questions, they nevertheless offered a richer basis for responsive comments. However, the relationship between very long postings and levels of interactivity is complex, and showed no statistical significance in the Chisquare analysis. Qualitative analysis suggests that when a writer's opinion is controversial, it provokes others to share relevant personal experiences, or raises a new set of questions; these complex postings can be highly interactive. But postings where a writer appears to have covered the subject comprehensively can be less interactive, possibly because other students have difficulty finding something new to say.

Even the postings that produce large numbers of responses are not necessarily the most helpful in generating further discussion. There was one individual among the subjects who was responsible for more than his share of lengthy postings, and his longer contributions mostly consisted of detailed analysis. Others in his class would often wait for him to respond first and many would then contribute very short postings agreeing with his point of view. On some occasions, though, these thought-provoking contributions sparked off some of the most challenging and complex debates in the data set. It seems that in the data overall, the positive and negative effects of these postings cancelled each other out.

The data for AUDIENCE indicate that postings intended for a broad audience, that is, more than one person, and for both instructor and other students, are more likely than not to be interactive. Although the variable NAME, certainly a marker of social presence, was not found to be a predictor of interactivity on its own, the vocative speech act was a frequent device used to indicate the intended audience of a posting, usually limiting the audience to one person. Indirectly then, naming does appear to be a possible negative predictor of interactivity.

We were somewhat surprised not to see a relationship between the independent variables FTA, SP, and NAME and the dependent variable INTERACT. In the case of FTAs, this is positive in one respect: they are not negative predictors of INTERACT. While it would be advantageous for a quality learning experience to have FTAs positively correlate with INTERACT, their statistical neutrality in this regard is still a positive attribute in light of Anderson's online learning model (2004). In fact, though, we do find in our qualitative analysis that some FTAs do have a positive relationship with increased interactivity, namely FTAs that are direct questions with politeness devices.

In addition, as suggested by Rourke et al. [15] and Tu and McIsaac [20], we found no relationship between expressions of social presence, i.e. naming, humor, emoticons, and the presence of phatic speech, and interactivity. While a high degree of expressed social presence is considered desirable for building a learning community [6, 15, 20], it seems possible to have a quality interactive asynchronous discussion without such markers.

Among indicators of social presence, we were particularly interested in NAME, even though it was not shown to have a relationship to INTERACT. However, we plan to do further qualitative analysis of naming in our data since the present study reveals it to be a speech act that interacts in a complex way with FTAs and with the indication of the intended audience. In particular, the use of naming as an FTA intensifier needs further study. We have very few instances of this in our data, so it remains to be seen 
what relationship, if any, this use of the vocative has on interactivity.

\section{IMPLICATIONS FOR ONLINE LEARNING AND TEACHING}

Interactivity in ACMC may be enhanced by the presence of direct questions in postings, broadening of intended audiences, and by consideration of the impact of length on the interactivity of postings. It would be possible to train students as to these particular written behaviors in such a way as to enhance interactivity in ACMC. It would also be possible for instructors to construct tasks that would encourage more interactive behavior. While discourse training in ACMC is not an uncontroversial subject, and it remains to be seen exactly what effect such training would have on the quality of discourse, there is some evidence for the positive role of structure and instructor presence in online learning [5].

\section{LIMITATIONS OF THE STUDY}

Among other variables, the study was unable to account for off-line interaction among class members, such as face-to-face or telephone communication; outside-of-class online interaction, such as emailing, or talking on SKYPE; or developing or existing social hierarchy among group members.

The results of the present study call for further qualitative analysis, especially with respect to question types, postings of extreme length, individual markers of social presence, and consideration of highly interactive postings.

Results of the study are not generalizable to a population of online learners outside of the courses in the study. However, the sample size is large enough to provide meaningful comparison between this group and other online learners.

\section{DIRECTIONS FOR FUTURE RESEARCH}

The quantitative results lead us to a qualitative analysis of the nature of interactivity. We are now examining adjacency pairs and longer exchanges, looking particularly at the quality of interactivity with respect to question types, speech acts, and individual markers of social presence, such as naming, humor, and phatic speech. In addition, further research is needed with respect to the nature of social and power relationships in online learning communities. Of particular value would be the application of conversation analysis and ethnographic methodology.

\section{ABOUT THE AUTHORS}

Robert Williams teaches in the MA program in Teaching English as a Foreign Language at the American University in Cairo, Egypt. His research interest is in the linguistic aspects of online talk and he is currently assembling a corpus of asynchronous classroom talk to be published in early 2008.

Rachel Humphrey teaches fifth grade elementary school in London, UK and is studying for an MA in Psycholinguistics and Neurolinguistics at the University of Essex. She has a MA in Teaching English as a Foreign Language from the American University in Cairo where she taught for two years in the English Language Institute. She has presented papers at EgypTESOL and TESOL Arabia. 


\section{REFERENCES}

1. Vygotsky, L. Mind in Society: The Development of Higher Psychological Processes. Cambridge, MA: Harvard University Press, 1978.

2. Lave. J. and E. Wenger. Situated Learning: Legitimate Peripheral Participation. Cambridge: University of Cambridge Press, 1991.

3. Garrison, R. and T. Anderson. E-Learning in the 21st Century: A Framework for Research and Practice. New York: Rutledge Flamer, 2003.

4. Anderson, T. Toward a theory of online learning. In T. Anderson and F. Elloumi (eds.), Theory and Practice in Online Learning. Athabasca University, 2004. http://cde.athabascau.ca /online_book/ch2.html.

5. Garrison, R. and M. Cleveland-Innes. Facilitating cognitive presence in online learning: Interaction is not enough. The American Journal of Distance Education 19(3): 133-148, 2005.

6. Goodfellow, R. and A. Hewling. Reconceptualizing Culture in Virtual learning Environments: from an 'essentialist' to a 'negotiated' perspective. E-learning 2(4): 355-67, 2005.

7. Barab, S., J. Makinster, J. Moore, D. Cunningham and ILF Design Team. Designing and building an online community: The struggle to support sociability in the inquiry learning forum. Educational Technology Research and Development 49(4): 71-96, 2001.

8. Wenger, E. Communities of Practice: Learning, Meaning, and Identity. Cambridge: Cambridge University Press, 1998.

9. Paloff, R. and K. Pratt. Building Learning Communities in Cyberspace. San Francisco: JosseyBass, 1999.

10. Barbules, N. Does the internet constitute a global educational community? In N. Barbules and C. Torres (eds.), Globalization and Education: Critical Perspectives, 323-356. London: Routledge, 2000.

11. Jonassen, D. Thinking technology: Toward a constructivist model. Educational Technology 34(4): 34-37, 1994.

12. Jonassen, D., K. Peck and B. Wilson. Learning with Technology: A Constructivist Perspective. Upper Saddle River, NJ: Prentice Hall, 1999.

13. Jones, C. The conditions of learning in networks. In L. Dirckinck-Holmfeld, L. Lindström, B. Svendsen and M. Ponti (eds.), Conditions for Productive Learning in Networked Learning Environments. Aalborg, Sweden: Aalborg University/Kaleidoscope, 2004.

14. Lamy, M. and R. Goodfellow. "Reflective conversation" in the virtual language classroom. Language Learning and Technology 2(2): 43-61, 1999.

15. Rourke, L., T. Anderson, D. R. Garrison and W. Archer. Assessing social presence in asynchronous text-based computer conferencing. Journal of Distance Education 14(2): 2001. http://cade.athabascau.ca/vol14.2/rourke et al.html.

16. Walther, J., J. Anderson and D. Park. Interpersonal effects in computer-mediated interaction. Communication Research 21(4): 460-487, 1994.

17. Warschauer, M. Computer-mediated collaborative learning: Theory and practice. The Modern Language Journal 81(4): 470-481, 1997.

18. Sotillo, S. Discourse functions and syntactic complexity in synchronous and asynchronous communication. Language Learning and Teaching 4(1): 82-119, 2000.

19. Fahy, P. and M. Ally. Student learning style and asynchronous computer-mediated conferencing (CMC) interaction. The American Journal of Distance Education 19(1): 5-22, 2005.

20. Tu, C. and M. McIsaac. The relationship of social presence and interaction in online classes. The American Journal of Distance Education 16(3): 131-150, 2002.

21. Jeong, A. The combined effects of response time and message content on growth patterns of discussion threads in computer-supported collaborative argumentation. Journal of Distance Education 19(1): 36-53, 2004. 
22. Searle, J. Speech acts: An essay in the philosophy of language. Cambridge: Cambridge University Press, 1969.

23. Searle, J. A classification of illocutionary acts. Language in Society 5: 1-23, 1976.

24. Grice, H. P. Meaning. Philosophical Review 66: 1957.

25. Grice, H. P. Logic and Conversation. In D. Davidson and G. Harman (eds.), The Logic of Grammar. Encino, California: Dickenson, 1975.

26. Leech, G. Principles of Pragmatics. London: Longman, 1983.

27. Brown, P. and S. Levinson. Politeness: Some Universals in Language Usage. Cambridge, England: Cambridge University Press, 1987.

28. Goffman, E. Interaction Ritual: Essays on Face to Face Behavior. Garden City, New York: Anchor Books, 1967.

29. Nguyen, H. and G. Kellogg. Emergent identities in on-line discussions for second language learning. The Canadian Modern Language Review/la revue canadienne des langues vivantes 62(1): 111-136, 2005.

30. Savignon, S. and W. Roithmeier. Computer-mediated communication: texts and strategies. CALICO Journal 21(2): 265-290, 2004.

31. Garrison, R., T. Anderson and W. Archer. Critical inquiry in a text-based environment: Computer conferencing in higher education. Unpublished Manuscript, 2000.

32. Jeong, A. The effects of linguistic qualifiers and intensifiers on group interaction and performance in computer-supported collaborative argumentation. International Review of Research in Open and Distance Learning 6(3): 2005. 